\title{
Modeling Compound to Rigidly Seal the Occlusal Window on Open Trays for Multi- unit Implant Impression
}

\author{
Jin-Joo Yoo, DDS, PhD' ${ }^{1}$ Joon-Ho Yoon, DDS, MSD, PhD²* \\ ${ }^{1}$ Assistant professor, Department of Prosthodontics, National Health Insurance Service Ilsan Hospital, Goyang, \\ Korea \\ ${ }^{2}$ Professor, Department of Prosthodontics, National Health Insurance Service llsan Hospital, Goyang, Korea \\ *Corresponding author: Joon-Ho Yoon, Department of Prosthodontics, National Health Insurance Service \\ Ilsan Hospital, 100 Ilsan-ro, Ilsandong-gu, Goyang-si, Gyeonggi-do 10444, Korea \\ Tel : +82-31-900-0627. eFax : +82-303-3448-7138. E-mail : yoonjuno@nhimc.or.kr
}

\begin{abstract}
Despite digitalization in dentistry, conventional impression techniques are still generally used for fabricating multi-unit implant prostheses. Among these techniques, the open-tray impression technique is known to be accurate. Open trays have occlusal windows to access impression coping, and the space might cause inaccurate impressions due to a lack of supporting structures. This technical report introduces a simple method to rigidly seal the occlusal window on open trays with type II modeling compounds.
\end{abstract}

Keywords: Dental implant, Direct impression, Modeling compound, Open tray

pISSN 2765-7833

eISSN 2765-7841

Journal of implantology and applied sciences 2021; 25(3): 141-146

https://doi.org/10.32542/implantology.2021015

Received: March 27, 2021

Revised: August 31, 2021

Accepted: September 1, 2021

ORCID

Jin-Joo Yoo

https://orcid.org/0000-0001-9346-723X

Joon-Ho Yoon

https://orcid.org/0000-0002-4571-7342

Copyright $\odot$ 2021. The Korean Academy of Oral \& Maxillofacial Implantology

This is an Open Access article distributed under the terms of the Creative Commons Attribution Non-Commercial License (http://creativecommons. org/licenses/by-nc/4.0/) which permits unrestricted non-commercial use, distribution, and reproduction in any medium, provided the original work is properly cited.

\section{I . Introduction}

The open tray impression technique is one of the common ways of taking impressions for implant prostheses and is known as the most accurate technique for multi-unit implants. ${ }^{1,2}$ All trays for open tray impression have occlusal holes or windows to access impression coping. However, there is no consensus on the material used to seal the hole or window. Unless the windows are sealed, impression material might overflow through the window and inhibit dentists from unscrewing impression coping after setting. ${ }^{3,4}$ In addition, a lack of supporting structures on the window space might distort the impression material.

Dentists can use various types of materials to seal the hole or window. ${ }^{5-9}$ Some types of wax, such as boxing wax or baseplate wax, are too resilient to support impression materials, especially in trays with large windows. It has been reported that other materials such as auto-polymerizing resin and plaster could be used to seal the window. ${ }^{5,6}$ Although they are more rigid than wax after hardening and could strongly support impression materials, it is 
difficult to handle in the oral cavity and require additional time to set it up.

Modeling compounds have been used to support impression materials during the impression procedure due to their dimensional stability. ${ }^{10}$ In addition, unlike auto-polymerizing resin or plaster, the working time of the modeling compound could easily be controlled by immersion in warm water and cooling. ${ }^{11}$ Therefore, we will introduce a simple way to seal the window on the trays for implant impression with a modeling compound.

\section{II . Technique}

1. Take impression with irreversible hydrocolloid and make a study model and individual tray with a window for the impression of implants (Fig. 1).

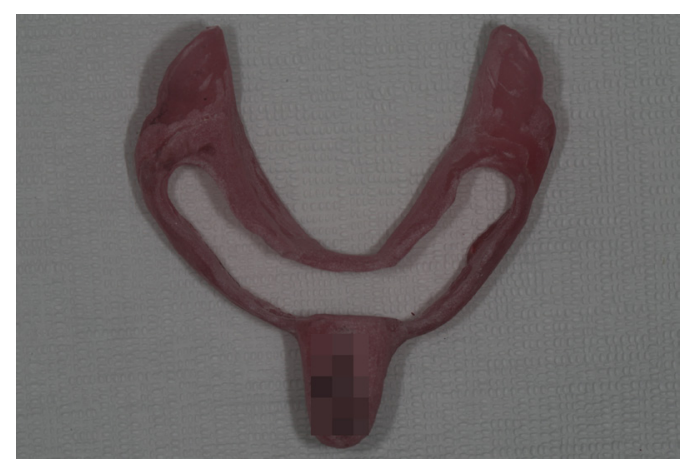

Fig. 1. Individual tray for direct implant impression.

2. Connect impression coping to the implant fixture and check the fit and seating of the tray (Fig. 2).

The tray was trimmed if prematurely contacted, inhibiting full seating.

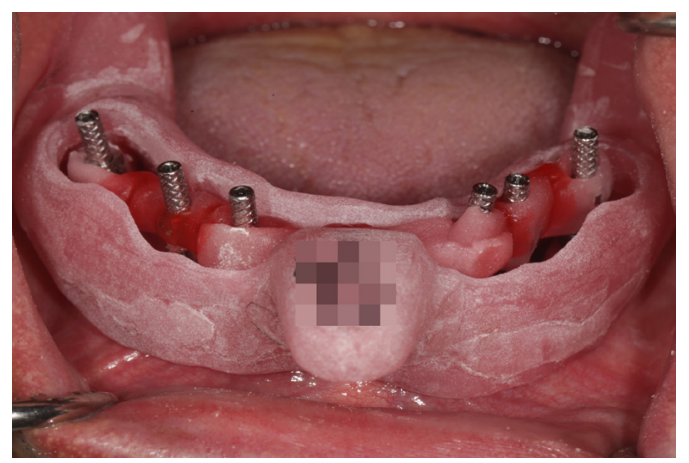

Fig. 2. Individual tray checked intra-orally after splinting impression copings with light-curing polymerizing acrylic resin and auto-polymerizing acrylic resin.

3. A cake-type modeling compound (Modeling Compound medium; GC Corporation, Tokyo, Japan) at $60^{\circ} \mathrm{C}(333.15 \mathrm{~K})$ water and cut into an appropriate size that covers the window on the tray (Fig. 3). 


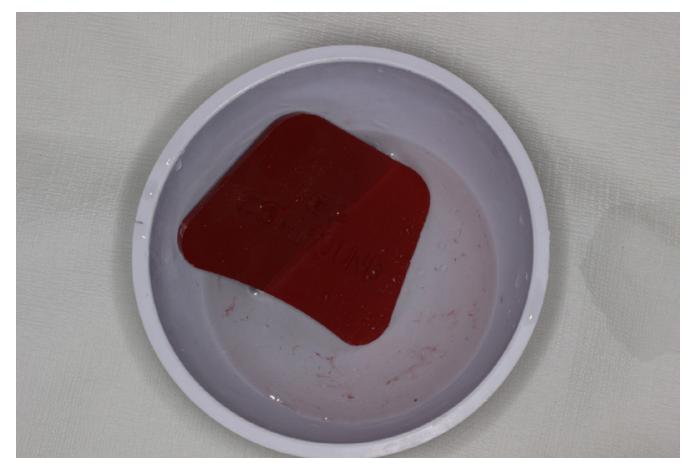

Fig. 3. Modeling compound being softened in $60^{\circ} \mathrm{C}(333.15 \mathrm{~K})$ water.

4. Cover the window on the tray with the modeling compound and press with the finger until the window is completely sealed. Use a heated wax spatula, if required. Strictly ensure that the material is not engaged in the tray.

5. Soften the modeling compound and insert the tray into the mouth.

6. The tray is cooled in cold water as soon as it is pulled out from the mouth to prevent distortion.

7. The inner surface of the tray is checked, and the contact area is removed by approximately $2 \mathrm{~mm}$ between the modeling compound and impression coping using No. 25 blade (Ailee surgical blade No. 25; Ailee Co., Ltd, Busan, Korea) (Figs. 4 and 5).

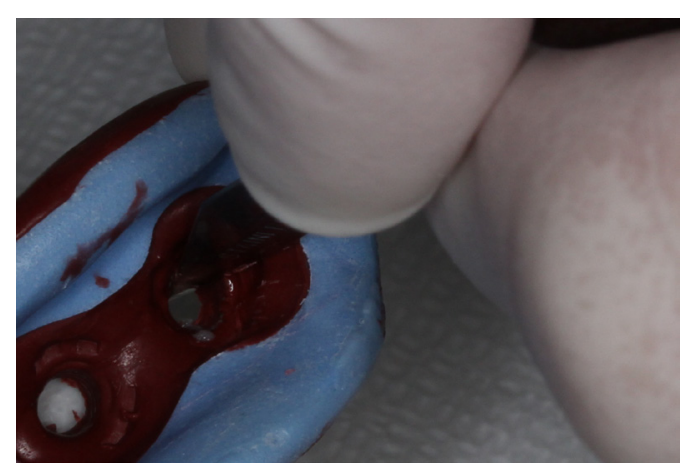

Fig. 4. Cutting off the contact area with No. 25 blade to remove interference and make space for impression material.

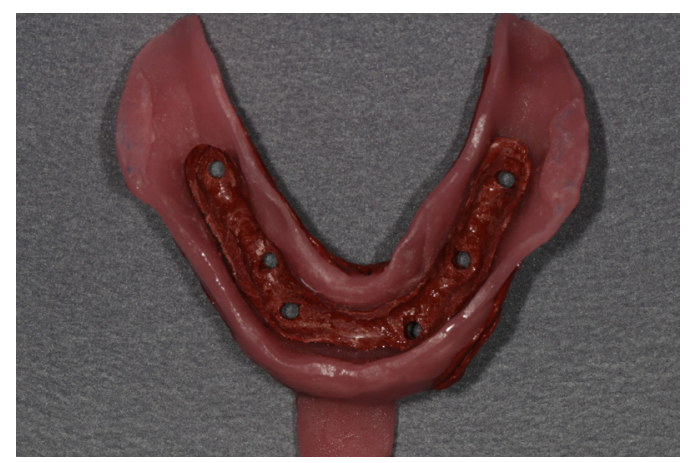

\section{Fig. 5. Cut inner surface.}


8. Make sure the tray is fully seated without interference.

9. An open-tray implant impression is made with polyether (3M ESPE Soft Monophase; 3M Oral Care, St. Paul, USA) to make implant-supported prostheses (Figs. 6-8).

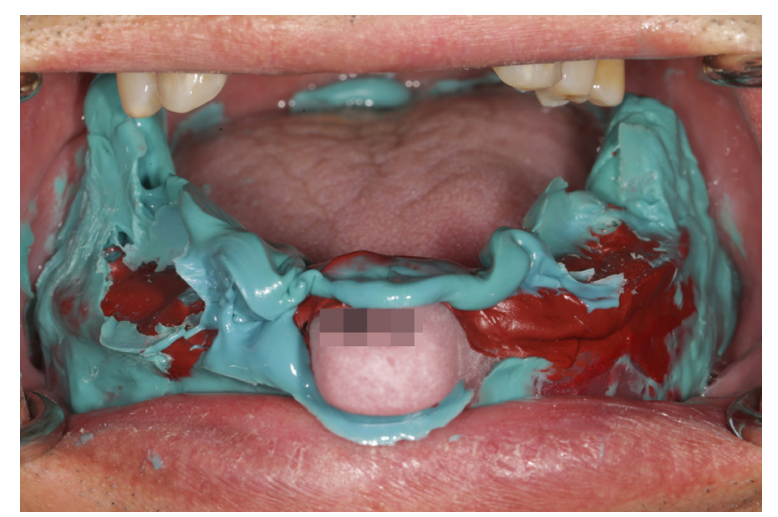

Fig. 6. Taking impression using the open tray covered with modeling compound.

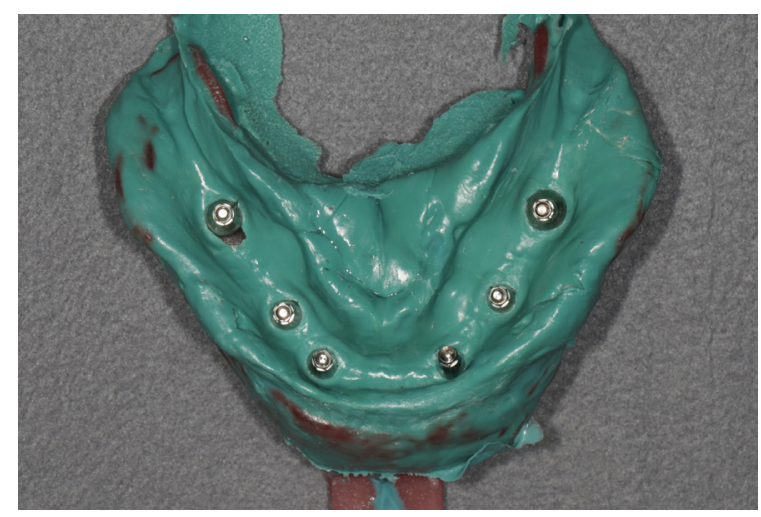

Fig. 7. Definitive impression body using the open tray covered with modeling compound.

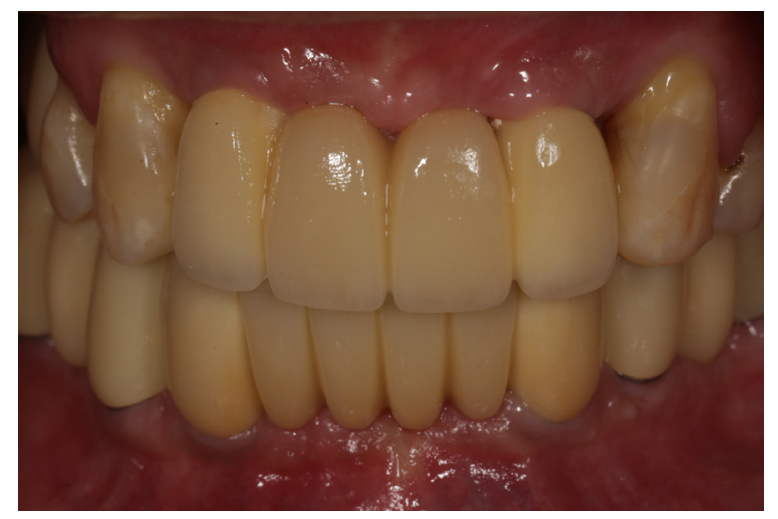

Fig. 8. Definitive implant-supported mandibular full-arch prostheses using the open tray covered with modeling compound. 


\section{Discussion}

It is not necessary to use a modeling compound when the trays have only a tiny hole for unscrewing. It is more appropriate for cases with multi-unit implants compared to single implants. This is because the more implants are involved, the larger the hole or window is made on the tray, which requires additional support for impression materials.

The following should be considered when using a modeling compound as the sealing material. First, when softening the modeling compound, an open flame might cause overheating or nonhomogeneous softening. ${ }^{10}$ It is recommended to use a water bath and to verify that the modeling compound is evenly softened by tactile sensation. Second, when inserting the tray into the mouth after softening the modeling compound, the modeling compound should not be separated from the tray or torn. Third, ensure that impression materials take the optimal thickness between the impression coping and modeling compound. Impression copings generally have complex structures that are retained within the impression body. If the inner surface of the modeling compound does not have adequate relief, it can cause undesirable distortion. $^{12}$

Using a modeling compound takes more time compared to using resilient wax or not sealing the hole or window. However, it enables the tray to firmly support the impression coping and materials, especially in multi-unit implant impressions. In addition, it is simpler than the existing method using plaster, and it is easier to control the working time than the method using auto-polymerizing resin or plaster. ${ }^{5,6}$ It has been reported that the splint technique is more accurate than the nonsplint technique in multi-unit implant impression. ${ }^{13}$ Considering that the modeling compound could hold impression copings more rigidly compared to resilient wax during implant impression, it can be suggested that a modeling compound has a similar function to splint impression copings. Future experimental and clinical researches are needed to determine whether the impressions obtained by this method are more accurate than those obtained by the conventional method.

\section{IV . Conclusion}

This technical report introduced a simple way to seal the window on a tray with a modeling compound conventionally used for fabricating individual trays. This method would modify the tray faster than when using plaster or auto-polymerizing resin and is more rigid compared to when using resilient wax; thus, the tray can be suitable for open tray implant impression. 


\section{References}

1. Kim JH, Kim KR, Kim S. Critical appraisal of implant impression accuracies: A systematic review. J Prosthet Dent 2015;114:185-92.e1.

2. Moreira AH, Rodrigues NF, Pinho AC, Fonseca JC, Vilaça JL. Accuracy Comparison of Implant Impression Techniques: A Systematic Review. Clin Implant Dent Relat Res 2015;17:e751-64.

3. Bhansali S, Bhansali SP, Negi P. A modified open tray implant impression technique for limited mouth opening. J Prosthet Dent 2017;118:116-7.

4. Jung SR, Bashutski JD. Method to simplify a direct implant impression using an extended guide pin. J Prosthet Dent 2010;104:137-8.

5. Ozcelik TB, Yilmaz B. A functional open-tray impression technique for implant-retained overdenture prostheses. J Oral Implantol 2012;38:617-9.

6. Eid N. An implant impression technique using a plaster splinting index combined with a silicone impression. J Prosthet Dent 2004;92:575-7.

7. Windhorn RJ, Gunnell TR. A simple open-tray implant impression technique. J Prosthet Dent 2006;96:220-1.

8. Wolfart S, Yilmaz B. A technique for facilitating open-tray implant impressions. J Prosthet Dent 2019;122:417-9.

9. Bhakta S, Vere J, Calder I, Patel R. Impressions in implant dentistry. Br Dent J 2011;211:361-7.

10. Modica R, Mainoldi G. Secondary softening of modeling compound for copper band impressions. J Prosthet Dent 1983;49:361-2.

11. Klein IE, Goldstein BM. Physiologic determinants of primary impressions for complete dentures. J Prosthet Dent 1984;51:611-6.

12. Valderhaug J, Fløystrand F. Dimensional stability of elastomeric impression materials in custommade and stock trays. J Prosthet Dent 1984;52:514-7.

13. Lee H, So JS, Hochstedler JL, Ercoli C. The accuracy of implant impressions: A systematic review. J Prosthet Dent 2008;100:285-91. 